\title{
Factors Influencing the Temperature-programmed Reduction Profiles of Vanadium Pentoxide
}

\author{
By Hans Bosch, ${ }^{*}$ Bert J. Kip, Jan G. van Ommen and Paul J. Gellings
}

Twente University of Technology, Department of Chemical Technology, P.O. Box 217, 7500 AE Enschede, The Netherlands

\section{Received 28th November, 1983}

The temperature-programmed reduction (t.p.r.) of bulk $\mathrm{V}_{2} \mathrm{O}_{5}$ has been examined as part of a study of the reducibility of $\mathrm{V}_{2} \mathrm{O}_{5}$-containing catalysts. T.p.r. profiles have been studied as a function of flow rate, heating rate and sample weight. From experiments at different flow rates it is concluded that the order of the reduction rate in hydrogen is low or even zero. A rule of thumb has been derived to provide an easy check on possible exhaustion of hydrogen in the feed. The influence of sample weight and heating rate is explained in terms of the formation of water in the sample during reduction. The reduction of bulk $\mathrm{V}_{2} \mathrm{O}_{5}$ to $\mathrm{V}_{2} \mathrm{O}_{3}$ proceeds in several steps; intermediate species include $\mathrm{V}_{6} \mathrm{O}_{13}$ and $\mathrm{VO}_{2}$. The apparent activation energy of $c a$. $200 \mathrm{~kJ} \mathrm{~mol}^{-1}$ indicates that solid-state diffusion influences the reduction process of $\mathrm{V}_{2} \mathrm{O}_{5}$.

Vanadium oxide based catalysts are used in many industrial oxidation processes. ${ }^{1}$ Among many other authors Roozeboom et al. $^{2}$ studied the selective oxidation of methanol over such catalysts. Recently, van Hengstum et al. ${ }^{3}$ reported results on the selective oxidation of toluene over $\mathrm{V}_{2} \mathrm{O}_{5} / \mathrm{TiO}_{2}$.

According to the oxidation-reduction mechanism, ${ }^{4}$ lattice oxygen plays an important role. Sachtler et al..$^{5}$ showed that the rate at which the bond strength of the lattice oxygen increases with the degree of reduction influences the selectivity.

In the present study temperature-programmed reduction ${ }^{6}$ (t.p.r.) has been used to investigate the different types of oxygen present in vanadium oxide which may be involved in the oxidation process over such catalysts. T.p.r. is a relatively new technique used to characterise reducable materials. The reduction is measured by monitoring $\mathrm{H}_{2}$ consumption while increasing the temperature of the sample at a constant rate. In this way, one or more reduction peaks occur at different temperatures and the reduction profile or 'spectrum' can be obtained easily.

In the case of heterogeneous catalysts, the compounds to be reduced are present on the surface or are potentially available to the surface. This method can therefore serve as a powerful tool to obtain 'fingerprint' characterisations of the reducibility of catalysts. ${ }^{7}$ Hurst et al. ${ }^{8}$ have recently given an excellent review of both the theoretical background and the applications of the technique. However, it is difficult to compare t.p.r. spectra obtained by different investigators. The conditions reported in the literature differ widely in $\mathrm{H}_{2}$ concentration and flow rate and in sample size and pretreatment. Some significant examples are given in table 1. The parameters mentioned do not affect t.p.r. profiles independently but it is very likely that the optimum conditions differ from one system to another because of large differences in the reducibilities of the materials investigated. The information obtained from t.p.r. profiles is merely comparative. A quantitative approach is difficult because of the complexity of the bulk oxide reduction processes thought to be taking place in the reduction of different types of catalysts. ${ }^{9}$ 
Table 1. Experimental conditions used in t.p.r. studies

\begin{tabular}{cccc}
\hline $\begin{array}{c}\text { sample size } \\
\left(\mathrm{H}_{2} \text { consumed }\right. \\
/ \mu \mathrm{mol})\end{array}$ & \multicolumn{1}{c}{ pretreatment } & $\begin{array}{c}\text { volume flow } \\
\text { rate } / \mathrm{cm}^{3} \\
\mathrm{~min}^{-1}\end{array}$ & $\mathrm{H}_{2}(\%)$ \\
\hline & $1 \mathrm{~h}$ at $453 \mathrm{~K}$ in $5 \% \mathrm{O}_{2}^{b, d}$ & $5^{b}$ & $4-6^{b, d, i, j, l, m}$ \\
$40-60^{a}$ & $2 \mathrm{~h}$ at $373 \mathrm{~K}$ in vacuo & $10^{a, g, i}$ & $8^{g}$ \\
$70-100^{b}$ & $1 \mathrm{~h}$ at $773 \mathrm{~K}$ in dry air & $18-20^{e, h, i}$ & $15^{f}$ \\
$1000-1700^{c}$ & $4 \mathrm{~h}$ at $773 \mathrm{~K}$ in $\mathrm{O}^{g}$ & $37^{k, l}$ & $66^{e, h, g}$ \\
& $1 \mathrm{~h}$ at $823 \mathrm{~K}$ in dry air & & \\
\hline
\end{tabular}

${ }^{a}$ Ref. (6); ${ }^{b}$ ref. (21); ${ }^{c}$ ref. (22); ${ }^{d}$ ref. (23); ${ }^{e}$ ref. (10); ${ }^{f}$ ref. (11); ${ }^{g}$ ref. (24); ${ }^{h}$ ref. (13); ${ }^{i}$ ref. (25); ${ }^{j}$ ref. (7); ${ }^{k}$ ref. (14); ${ }^{l}$ ref. (27); ${ }^{m}$ ref. (12); ${ }^{n}$ ref. (26).

The aim of the present work is to study the reduction behaviour of bulk $\mathrm{V}_{2} \mathrm{O}_{5}$ as part of the reduction of vanadium oxide containing catalysts. This paper presents a systematic study of the parameters which may govern the resolution of t.p.r. profiles, such as sample mass, heating rate, volume flow rate, grain size and the presence of water.

\section{EXPERIMENTAL}

\section{APPARATUS}

The t.p.r. apparatus used in this study was constructed according to the descriptions given previously, ${ }^{6,7}$ with the following changes being made. First, the reference flow through the thermal-conductivity detector (t.c.d.) was regulated separately and all gas lines were provided with flow and pressure controllers. Secondly, the $\mathrm{H}_{2}+\mathrm{Ar}$ stream from the reactor and dryer was diluted by an additional argon flow, typical volume flow rates being: $\mathrm{H}_{2}+\mathrm{Ar} 10 \mathrm{~cm}^{3} \mathrm{~min}^{-1}$, Ar (diluent) $10 \mathrm{~cm}^{3} \mathrm{~min}^{-1}$ and Ar (reference) $20 \mathrm{~cm}^{3} \mathrm{~min}^{-1}$ [all gas volumes are expressed at room temperature $(298 \mathrm{~K}$ ) and atmospheric pressure]. This set-up minimizes the change in flow rate caused by $\mathrm{H}_{2}$ uptake. Ar instead of $\mathrm{N}_{2}$ was used to avoid possible nitride formation, e.g. in the case of Fe-containing samples. ${ }^{10}$ Finally, the quartz reactor was made as small as possible (i.d. $4 \mathrm{~mm}$, reactor dead space $3 \mathrm{~cm}^{3}$, total dead space $12 \mathrm{~cm}^{3}$ ) to avoid peak-widening by back-mixing. The temperature was measured with a thermocouple outside the reactor, its tip positioned near the sample, to prevent reduction of the thermocouple wall. Blanks were carried out to correct for the temperature difference of $9 \mathrm{~K}$ involved.

\section{MATERIALS}

All gases used were of the highest purity available commercially. Traces of oil were removed by activated charcoal filters and moisture was removed by molecular sieves. All experiments were carried out with $9 \% \mathrm{H}_{2}$ in argon. $\mathrm{V}_{2} \mathrm{O}_{5}$ for use in bulk oxide experiments was supplied by Merck (pro analysis) or freshly prepared by decomposition of $\mathrm{NH}_{4} \mathrm{VO}_{3}$ (Merck) or vanadyl acetylacetonate (Baker). Some t.p.r. experiments were performed starting with $\mathrm{VO}_{2}$ (Jansen Chemicals). The main pretreatment of the samples consisted of heating in air at $773 \mathrm{~K}$ for $1 \mathrm{~h}$, as recommended by Thomas ${ }^{10}$ and Yao, ${ }^{11}$ to assure good reproducibility.

\section{ADDITIONAL TECHNIQUES}

The results of some t.p.r. experiments were compared with the weight losses in similar thermogravimetric experiments (Du Pont 951 thermogravimetric analyser). In some cases, X-ray diffraction was used to identify the phases present after partial or complete reduction (Philips PW 1025.25 diffractometer). 


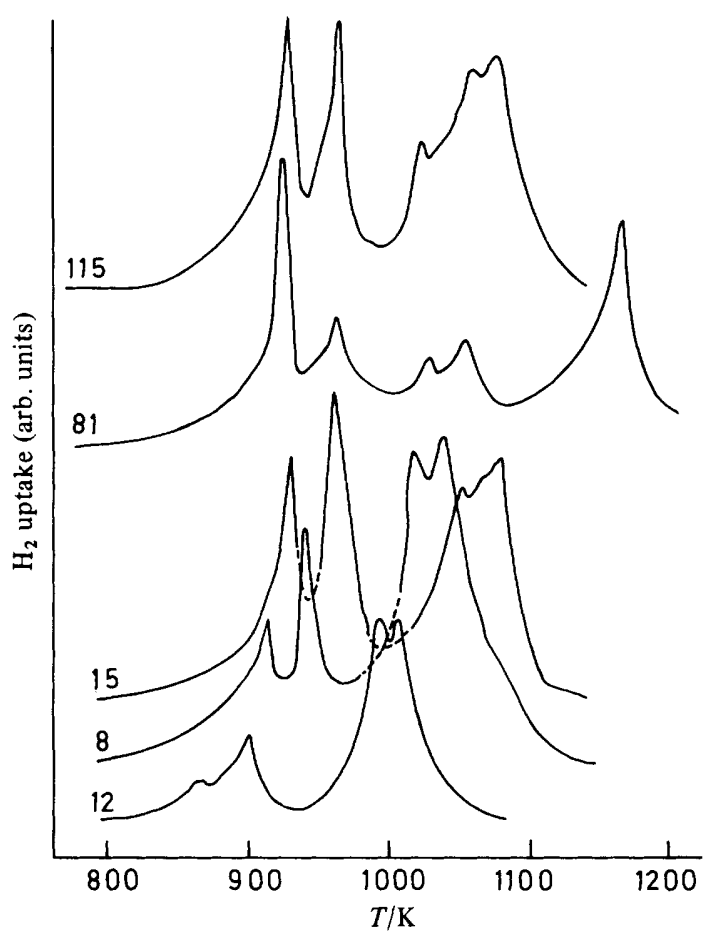

Fig. 1. Influence of heating rate on t.p.r. spectra. Volume flow rate, $10 \mathrm{~cm}^{3} \mathrm{~min}^{-1}, 9 \% \mathrm{H}_{2}$. Run (12) sample weight $14.8 \mathrm{mg}$, heating rate $4.6 \mathrm{~K} \mathrm{~min}^{-1}$; run (8) sample weight $16.2 \mathrm{mg}$, heating rate $5.6 \mathrm{~K} \mathrm{~min}^{-1}$; run (15) sample weight $14.9 \mathrm{mg}$, heating rate $9.8 \mathrm{~K} \mathrm{~min}^{-1}$; run (81) sample weight $10.9 \mathrm{mg}$, heating rate $16.4 \mathrm{~K} \mathrm{~min}^{-1}$; run (115) sample weight $4.3 \mathrm{mg}$, heating rate $16.1 \mathrm{~K} \mathrm{~min}^{-1}$.

\section{RESULTS}

The reduction of bulk $\mathrm{V}_{2} \mathrm{O}_{5}$ proceeds in at least four different steps. Typical results are given in fig. 1. At suitable conditions a slow rise in $\mathrm{H}_{2}$ consumption is followed by two sharp, well resolved peaks. At $8 \mathrm{~K} \mathrm{~min}^{-1}$ and $10 \mathrm{~cm}^{3} \mathrm{~min}^{-1}$ the temperatures for the maximum reduction rates of the first two peaks are $930 \pm 2$ and $964 \pm 3 \mathrm{~K}$, respectively.

The next two peaks do not show such good separation, but their positions can be reproduced within \pm 5 and $\pm 8 \mathrm{~K}$, respectively. The increase in reduction rate at the onset of the third peak is significantly higher than that at the first peak. This phenomenon is discussed in the Discussion section.

A series of experiments was carried out to check the possible influence of heat-transport limitations. $10 \mathrm{mg} \mathrm{V}_{2} \mathrm{O}_{5}$ was either used undiluted or mixed with $65-270 \mathrm{mg}$ of quartz. All the peaks appeared at the same temperatures, within the limits given above. Thus heat-transport limitations are not present. Similarly, no significant change in peak positions was observed when t.p.r. results from measurements with grains of diameter $0.3-0.6 \mathrm{~mm}$ were compared with those for $\mathrm{V}_{2} \mathrm{O}_{5}$ powder (particle diameter $<50 \mu \mathrm{m}$ ); hence there are no mass-transport limitations either.

The residence-time distribution was measured by injection of hydrogen at the top 
Table 2. T.p.r. results as a function of heating rate

\begin{tabular}{|c|c|c|c|c|c|c|c|c|}
\hline \multirow[b]{2}{*}{ run } & \multirow{2}{*}{$\begin{array}{c}\text { heating } \\
\text { rate } / \mathrm{K} \\
\mathrm{min}^{-1}\end{array}$} & \multirow{2}{*}{$\begin{array}{l}\text { flow } \\
/ \mathrm{cm}^{3} \\
\mathrm{~min}^{-1}\end{array}$} & \multirow{2}{*}{$\begin{array}{c}\text { sample } \\
\text { weight } \\
/ \mathrm{mg}\end{array}$} & \multicolumn{4}{|c|}{ temperature of peak maximum $/ \mathrm{K}$} & \multirow[b]{2}{*}{ remarks } \\
\hline & & & & 1 st & $2 \mathrm{nd}$ & 3 rd & 4 th & \\
\hline 12 & 4.6 & 10 & 14.8 & 874 & 906 & 998 & 1011 & - \\
\hline 27 & 4.7 & 20 & 11.0 & 895 & 924 & 1005 & - & - \\
\hline 13 & 5.3 & 10 & 17.3 & 900 & 932 & 1009 & 1024 & - \\
\hline 8 & 5.6 & 10 & 16.2 & 920 & 952 & 1036 & 1052 & - \\
\hline 87 & 5.8 & 10 & 10.0 & 914 & 949 & 1029 & 1041 & - \\
\hline 29 & 6.1 & 20 & 11.1 & 924 & 961 & 1033 & 1045 & - \\
\hline 14 & 6.7 & 10 & 14.6 & 923 & 956 & - & - & - \\
\hline \multirow[t]{2}{*}{23} & 7.5 & 20 & 10.0 & 931 & 968 & 1038 & 1054 & - \\
\hline & 8.1 & 10 & $11 \pm 1$ & $930 \pm 2$ & $964 \pm 3$ & $1042 \pm 5$ & $1056 \pm 8$ & $\begin{array}{c}\text { average } \\
\text { of } 5 \\
\text { runs }\end{array}$ \\
\hline 89 & 8.3 & 20 & 10.9 & 930 & 962 & 1032 & 1055 & \\
\hline 15 & 9.1 & 10 & 14.9 & 932 & 968 & 1058 & 1076 & $\begin{array}{c}\text { 5th peak } \\
\text { at } \\
1088 \mathrm{~K}\end{array}$ \\
\hline 78 & 9.4 & 10 & 9.7 & 934 & 968 & 1054 & 1074 & \\
\hline 17 & 10.1 & 10 & 10.7 & 936 & 973 & 1059 & 1075 & $\begin{array}{c}5 \text { th peak } \\
\text { at } \\
1095 \mathrm{~K}\end{array}$ \\
\hline 25 & 10.6 & 20 & 11.1 & 941 & 975 & 1056 & 1067 & \\
\hline 79 & 11.2 & 10 & 9.9 & 936 & 974 & 1067 & 1084 & $\begin{array}{c}\text { 5th peak } \\
\text { at } \\
1093 \mathrm{~K}\end{array}$ \\
\hline 26 & 12.6 & 20 & 11.5 & 943 & 979 & 1056 & 1095 & \\
\hline 81 & 14.6 & 10 & 10.8 & 936 & 969 & 1034 & 1116 & $\begin{array}{c}\text { 5th peak } \\
\text { at } \\
1130 \mathrm{~K}\end{array}$ \\
\hline 115 & 16.1 & 10 & 4.3 & 931 & 958 & 1028 & 1070 & $\begin{array}{c}\text { 5th peak } \\
\text { at } \\
1091 \mathrm{~K}\end{array}$ \\
\hline
\end{tabular}

of the catalyst bed. The peak widening, caused by diffusion, was $<2 \mathrm{~K}$. Thus, plug flow can be assumed to occur. All temperatures mentioned in this paper have been corrected for the residence time $(50 \mathrm{~s})$. This correction was usually $10-20 \mathrm{~K}$.

Changing the sample size from 5 to $43 \mathrm{mg}$ did not change the position of the first two peaks. With samples of $>20 \mathrm{mg}$, the third and fourth peaks shifted to higher temperatures. Similarly, at heating rates of $7 \mathrm{~K} \mathrm{~min}^{-1}$ and higher, variation of volume flow rates from 10 to $20 \mathrm{~cm}^{3} \mathrm{~min}^{-1}$ did not change the peak positions either; some examples of such experiments are given in table 2. The lower flow rates seem to shift the first peak to a slightly lower temperature, e.g. compare runs 17 and 25 . Since typical $\mathrm{H}_{2}$ conversions amount to $20-60 \%$, changes in hydrogen concentration because of variations in sample weight and flow rate do not influence these results. This suggests that, although the inlet hydrogen concentration was not varied, the order in hydrogen is low or even zero.

Some t.g. experiments were carried out to identify the compounds formed successively in the different reduction steps. In these experiments samples were cooled in nitrogen after the first peak appeared and then examined by X.r.d. In subsequent runs, similar 
Table 3. Compounds detected by X.r.d. at various stages in the reduction of $\mathrm{V}_{2} \mathrm{O}_{5}{ }^{a}$

\begin{tabular}{|c|c|c|c|c|c|c|}
\hline \multirow{2}{*}{$\begin{array}{l}\text { compounds } \\
\text { detected }\end{array}$} & \multirow{2}{*}{$\begin{array}{c}\mathrm{V}_{2} \mathrm{O}_{5} \\
\text { ortho- } \\
\text { rhombic }\end{array}$} & \multirow{2}{*}{$\begin{array}{c}\mathrm{V}_{6} \mathrm{O}_{13}, \\
\text { mono- } \\
\text { clinic }\end{array}$} & \multirow{2}{*}{$\begin{array}{l}\mathrm{VO}_{2}, \\
\text { mono- } \\
\text { clinic }\end{array}$} & \multirow{2}{*}{$\begin{array}{l}\mathrm{V}_{2} \mathrm{O}_{3} \\
\text { hexag- } \\
\text { onal }\end{array}$} & \multicolumn{2}{|c|}{$\begin{array}{c}\text { t.g.a., } 10 \mathrm{~K} \mathrm{~min}-1,20.24 \mathrm{mg} \mathrm{V}_{2} \mathrm{O}_{5} \\
\text { weight change/mg }\end{array}$} \\
\hline & & & & & observed & theoretical \\
\hline $\begin{array}{l}\text { starting } \\
\text { compound }\end{array}$ & $\mathrm{s}$ & n.o. & n.o. & n.o. & 1.15 & 1.187 \\
\hline $\begin{array}{l}\text { reduction } \\
\text { terminated } \\
\text { before } 2 \text { nd peak }\end{array}$ & n.o. & $\mathrm{s}$ & $\mathrm{w}$ & n.o. & 0.625 & 0.593 \\
\hline $\begin{array}{l}\text { reduction } \\
\text { terminated } \\
\text { before 3rd peak }\end{array}$ & n.o. & n.o. & $\mathrm{s}$ & n.o. & 1.775 & 1.78 \\
\hline $\begin{array}{l}\text { final product } \\
\text { at } 1123 \mathrm{~K}\end{array}$ & n.o. & n.o. & n.o. & $\mathbf{s}$ & total 3.55 & total 3.56 \\
\hline
\end{tabular}

${ }^{a}$ s, strong; w, weak; n.o., not observed.

samples were cooled after the second and fourth peaks. The compounds identified by X.r.d. before and after these peaks are given in table 3. All the observed diffraction peaks could be labelled. Mainly $\mathrm{V}_{6} \mathrm{O}_{13}$ is formed after the first reduction step. In the second step, $\mathrm{V}_{6} \mathrm{O}_{13}$ is completely reduced to $\mathrm{VO}_{2}$ before subsequent reduction takes place. In the final product, formed at $1123 \mathrm{~K}$, only $\mathrm{V}_{2} \mathrm{O}_{3}$ can be detected. From this reduction stiochiometry the theoretical weight changes after the first, second and fourth peak were calculated. These theoretical values are also given in table 3 . They show good agreement with the values from the t.g. experiments. A number of t.p.r. runs are summarized in table 2 . The positions of the peaks move $c a$. $70 \mathrm{~K}$ toward higher temperatures when heating rates are increased from 5 to $16 \mathrm{~K} \mathrm{~min}^{-1}$. Gentry et $a l .{ }^{12}$ have given a method for calculating the apparent activation energy of the reduction from such changes. Assuming zero-order behaviour in hydrogen and that longitudinal mixing is absent (i.e. there is plug flow), they arrive at the equation:

$$
\ln \left(T_{\mathrm{m}}^{2} / \beta\right)=E / \boldsymbol{R} T_{\mathrm{m}}+\text { constant }
$$

where $T_{\mathrm{m}}$ is the temperature of the peak maximum $(\mathrm{K}), \beta$ is the heating rate $\left(\mathrm{K} \mathrm{s}^{-1}\right)$ and $E$ is the apparent activation energy $\left(\mathrm{kJ} \mathrm{mol}^{-1}\right)$. In the derivation of eqn (1), the underlying assumptions are that a purely chemical process is described, its rate being governed by an Arrhenius equation, and that a number of parameters are constant during the reduction of a particular compound. Application of eqn (1) to the positions of the first peak results in a surprisingly high value of the apparent activation energy of $c a .200 \mathrm{~kJ} \mathrm{~mol}^{-1}$ at heating rates of $5.6-10.1 \mathrm{~K} \mathrm{~min}^{-1}$. At lower as well as higher heating rates a marked deviation from the best straight line occurs.

The heating rate influences not only the peak positions but also the form of the t.p.r. profiles. Some significant examples are given in fig. 1. A heating rate of $<5 \mathrm{~K} \mathrm{~min}^{-1}$ results in very poor resolution of the first two peaks. A fifth peak can be observed with a rate $>10 \mathrm{~K} \mathrm{~min}^{-1}$ although this is not well resolved. At $16 \mathrm{~K} \mathrm{~min}^{-1}$, the change in the t.p.r. profile is even more pronounced [fig. 1, run (81)]: the second, third and fourth peaks have become smaller and the fourth and fifth peaks are now completely resolved. All profiles mentioned so far in relation to fig. 1 were measured with a sample weight of $c a .11-15 \mathrm{mg}$. T.p.r. experiments at $16 \mathrm{~K} \mathrm{~min}^{-1}$ with $4.3 \mathrm{mg}$ [fig. 1, run (115)] resulted in profiles similar to those obtained at $10 \mathrm{~K} \mathrm{~min}^{-1}$. 


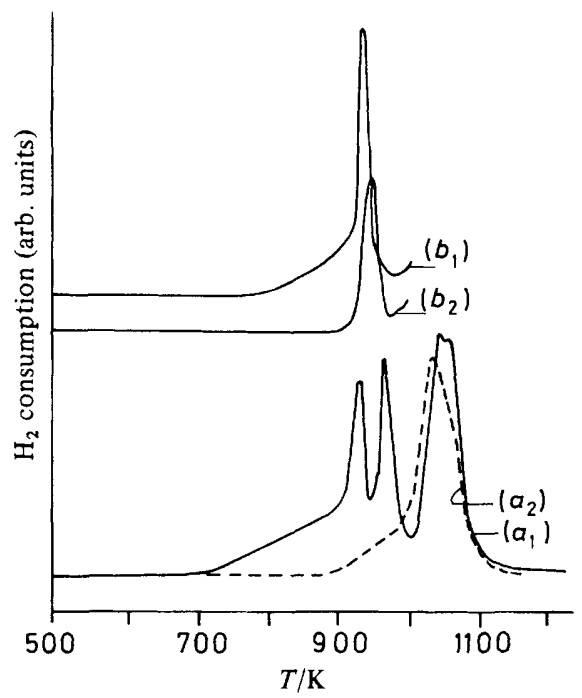

Fig. 2. Influence of $(a)$ crystal structure and $(b)$ prereduction on the onset of the first reduction peak. $\left(a_{1}\right)$ Reduction of $\mathrm{V}_{2} \mathrm{O}_{5}$ and $\left(a_{2}\right)$ reduction of $\mathrm{VO}_{2}$. $\left(b_{1}\right)$ First reduction peak of calcined $\mathrm{V}_{2} \mathrm{O}_{5}$ and $\left(b_{2}\right)$ reduction peak of prereduced and reoxidised $\mathrm{V}_{2} \mathrm{O}_{5}$.

Thus, sample weight and heating rate are not independent experimental parameters. Combined they determine the possibility of exhaustion of the feed and/or a possible influence of water, resulting in spectra which do not fit the usual pattern.

The first two t.p.r. peaks from the reduction of freshly prepared $\mathrm{V}_{2} \mathrm{O}_{5}$ (from ammonium vanadate or vanadyl acetylacetonate) are similar to those mentioned above, the only difference being a shift to a higher temperature: 953 and $944 \mathrm{~K}$, respectively, as compared with $930 \mathrm{~K}$ for the sample of $\mathrm{V}_{2} \mathrm{O}_{5}$ supplied by Merck. However, the third peak is broad and does not show resolution into two distinct peaks. Obviously the pretreatment was insufficient to produce similar structures.

Some t.p.r. experiments were performed starting from $\mathrm{VO}_{2}$ instead of $\mathrm{V}_{2} \mathrm{O}_{5}$ [fig. $2(a)$ ]. The first reduction peak differs from the corresponding peak starting from $\mathrm{V}_{2} \mathrm{O}_{5}$ in position and form and is observed at $1027 \mathrm{~K}$ as compared with $1037-1047 \mathrm{~K}$ for the third peak of the $\mathrm{V}_{2} \mathrm{O}_{5}$ profile. The reduction of $\mathrm{VO}_{2}$ starts relatively slowly as compared with that of $\mathrm{VO}_{2}$ obtained during the reduction of $\mathrm{V}_{2} \mathrm{O}_{5}$. However, the low-temperature part of both profiles in fig. $2(a)$ is similar.

The latter results, as well as the high value of the apparent activation energy, suggest that the structure of the solid phase plays an important role. To investigate this, the following t.g. experiments were conducted. A regular reduction experiment was carried out with $\mathrm{V}_{2} \mathrm{O}_{5}$, but the sample was cooled as soon as the first reduction peak was completed [fig. $2(b)$ ]. The sample was reoxidized until constant weight, the final oxidation temperature not exceeding the temperature of the peak maximum. A starting weight corresponding to $\mathrm{V}_{2} \mathrm{O}_{5}$ was always obtained. After this, the reoxidized sample was reduced again under the same conditions as before [fig. 2, run $\left(b_{2}\right)$ ]. Although the peak maxima of runs $\left(b_{1}\right)$ and $\left(b_{2}\right)$ appeared at the same temperature, the onset of the reduction in run $\left(b_{2}\right)$ started at a markedly higher temperature. This behaviour is similar to that for the reduction of $\mathrm{VO}_{2}$ as mentioned above: reduction of $\mathrm{VO}_{2}$ as an intermediate product proceeds in a similar way to the reduction of $\mathrm{V}_{2} \mathrm{O}_{5}$ in $\operatorname{run}\left(b_{2}\right)$. 


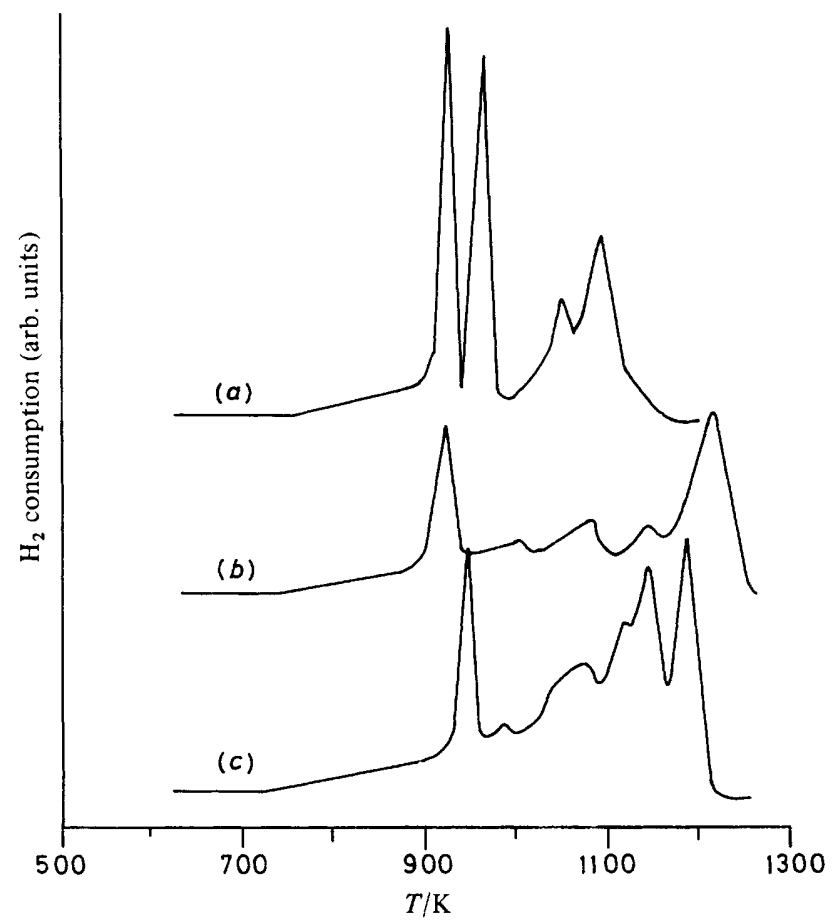

Fig. 3. Influence of water vapour on t.p.r. profiles. (a) Heating rate $10 \mathrm{~K} \mathrm{~min}^{-1}$; $(b)$ heating rate $20 \mathrm{~K} \mathrm{~min}^{-1} ;(c)$ heating rate $10 \mathrm{~K} \mathrm{~min}^{-1}$, reduction with $\mathrm{Ar}+\mathrm{H}_{2}$ with $3 \% \mathrm{H}_{2} \mathrm{O}$.

Finally, the influence of water on the reduction profile was investigated by t.g. experiments using $\mathrm{H}_{2}+\mathrm{Ar}$ saturated at room temperature with water. The presence of water has a considerable affect on the reduction profile, as can be seen in fig. 3 by comparing run $(a)$ (no $\mathrm{H}_{2} \mathrm{O}$ ) and run $(c)\left(\mathrm{H}_{2} \mathrm{O}\right.$ added). The number of peaks is increased and the temperature at which the reduction is completed is higher. A similar result can be obtained by just increasing the heating rate, as can be seen from fig. 3 , run $(b)$.

\section{DISCUSSION}

Temperature-programmed reduction has been claimed to be a successful ' fingerprint method' for the characterisation of reducible species. This section will focus on the significance of the 'fingerprints' obtained.

Reported t.p.r. spectra for $\mathrm{V}_{2} \mathrm{O}_{5}$ appear to differ notably from our results. Roozeboom et al. ${ }^{13}$ found one single reduction peak at $c a .800 \mathrm{~K}\left(5 \mathrm{~K} \mathrm{~min}^{-1}, 2 \mathrm{mg}\right.$ sample weight as calculated from their data). Bond ${ }^{14}$ obtained spectra from $\mathrm{V}_{2} \mathrm{O}_{5}$ (Merck) similar to ours, the first two peaks shifted only slightly, the last of these not being resolved, as in our case, into at least two peaks $\left(5 \mathrm{~K} \mathrm{~min}^{-1}, 100 \mathrm{mg}\right)$. Possible reasons for these different results are discussed below.

It has already been shown in the Results section that the reduction probably proceeds as follows:

$$
\mathrm{V}_{2} \mathrm{O}_{5} \rightarrow \frac{1}{3} \mathrm{~V}_{6} \mathrm{O}_{13} \rightarrow 2 \mathrm{VO}_{2} \rightarrow \mathrm{V}_{2} \mathrm{O}_{3} \text {. }
$$

The first two peaks (fig. 1) correspond to the first two steps. The third and last t.p.r. peaks together represent the last step, which clearly comprises more than one step; $\mathrm{V}_{6} \mathrm{O}_{11}$ is one of the possible intermediate compounds. 
Thus, distinct reduction steps show up as different peaks in the t.p.r. profile. When the place of a particular peak depends solely on kinetic parameters, the peak shift caused by changes in heating rate contains information on the apparent activation energy. Although such factors as surface composition, defects and geometry affect the reactivity of the reduction of even simple metallic oxides, ${ }^{9}$ it is very difficult to account for these factors in a non-isothermal case. ${ }^{8}$ Gentry et al. ${ }^{12}$ have shown, for the case of the reduction of copper-exchanged zeolites, that the influence of $\mathrm{H}_{2}$ concentration and flow rate can be described satisfactorily by means of a simple kinetic equation. The high value we obtained using this method for the reduction of bulk $\mathrm{V}_{2} \mathrm{O}_{5}$ suggests that the behaviour of this system is more complicated. Peaks other than the first one show that there are compounds which are not present in the starting material but are formed during the reduction. The local rate of formation will be different because of local oxygen gradients in the particles, depending on experimental conditions such as heating rate and volume flow rate. Thus that part of the spectrum not only contains information relating to the properties of the starting material but also reflects how the reduction proceeds, as determined by kinetics as well as by experimental parameters.

It is well documented how oxygen is removed from the $\mathrm{V}_{2} \mathrm{O}_{5}$ matrix. ${ }^{15,16}$ Oxygen species to be removed leave behind anionic vacancies which are not randomly distributed but lie in particular planes. Therefore, beyond a certain degree of reduction, the structure may change by just small displacements along those vacancyrich planes. The resulting structure is known as a shear structure. ${ }^{17}$

Reasoning along these lines, it can be understood why a relatively low heating rate does not resolve the first two peaks, in contrast to the results at higher heating rates. At a certain temperature the degree of reduction of the sample in run (12) (see fig. 1 ) is higher compared with that in run (15) because of its lower heating rate. Therefore, in the first case a second phase can be formed at lower temperatures. Because of the lower temperature, the conversion proceeds relatively slowly and the resulting peak is quite broad: shear structures might therefore be present in a larger proportion of the sample instead of a progression of stoichiometric compounds, as described above. Local regions may be converted into a new shear structure, whereas other parts are still in the initial structure. This might also explain the poor reproducibility of the peak positions at low heating rates (table 2) and also the deviation from an Arrhenius plot on the lower-temperature side.

Apart from the change in crystal structure because of the formation of shear structures, it has to be remembered that the temperature region in which the first peak appears (see table 2) is not far from the melting point of $\mathrm{V}_{2} \mathrm{O}_{5}(963 \mathrm{~K}$ ). This also gives rise to enhanced mobility of the ions in the matrix, which might contribute to the changes in crystal structure. However, this is probably not a significant process since prereduction and reoxidation in this temperature region do not influence the position of the subsequent rereduction peak (fig. 2). The influence of structural parameters may be reflected by a small shift of 10-20 K to higher temperatures starting from two kinds of freshly prepared $\mathrm{V}_{2} \mathrm{O}_{5}$ and one of $10-20 \mathrm{~K}$ to lower temperatures starting from $\mathrm{VO}_{2}$. Crystal structure and orientation affect the reducibility, ${ }^{13}$ but this is far more pronounced in supported systems, which may show shifts of several hundred degrees, as will be demonstrated in a subsequent paper.

With an increasing heating rate, the first peak shifts close $(20 \mathrm{~K})$ to the melting point of $\mathrm{V}_{2} \mathrm{O}_{5}$ and the second to the region where $\mathrm{V}_{6} \mathrm{O}_{13}$ is not stable. ${ }^{18}$ These two peaks show an upper limit and cannot shift further upon increasing the heating rate. At those heating rates no meaningful values of the apparent activation energy can be calculated, leaving only a relatively small range of $5-10 \mathrm{~K} \mathrm{~min}^{-1}$ in which the method of Gentry 
et al. can be applied. However, the value of $E$ obtained $\left(200 \mathrm{~kJ} \mathrm{~mol}^{-1}\right)$ is an indication of the occurrence of a solid-state diffusional process.

All experiments presented in this paper are thought to be free from heat- and/or (pore-diffusional-) mass-transport limitations. This does not hold for run (81), which is presented in fig. 1 to show that it is the combination of heating rate and sample weight which determines possible exhaustion of the feed $\mathrm{H}_{2}$. Comparison of run (81) $(10 \mathrm{mg})$ and run (115) $(4.3 \mathrm{mg})$ show that the same form of t.p.r. profile can be obtained, even at relatively high heating rates, provided that a suitable sample weight is used. The hydrogen feed rate should be high enough to match the highest possible oxygen removal rate. Regular checks should thus be made at the highest reduction rate to ensure that the gradient of the hydrogen concentration (along the reactor and across the particles) is sufficiently small. An equation which relates the maximum allowable sample weight and the amount of oxygen removed during a particular reduction step (a particular peak) can be derived as follows. Starting from the boundary condition $\phi_{\mathrm{H}_{2}}>r_{\text {red }} G_{\mathrm{MO}_{n}}$ (where $\phi_{\mathrm{H}_{2}}$ is the flow rate of $\mathrm{H}_{2} . r_{\text {red }}$ is the specific reduction rate and $G_{\mathrm{MO}_{n}}$ is the total sample weight) and assuming that all the oxygen involved in the particular step considered is removed at a constant rate during an interval $\Delta t=\Delta T_{\frac{1}{2}} / \beta$, this leads to the following constraint

$$
G_{\mathrm{MO}_{n}}<\phi_{\mathrm{H}_{2}} \frac{\Delta T_{1}}{\beta} \frac{M_{\mathrm{MO}_{n}}}{\mathrm{O} / \mathrm{M}}
$$

where $\Delta T_{\frac{1}{2}}$ is the peak width at half height, $\mathrm{O} / \mathrm{M}$ is the molar ratio of oxygen removed and metal present and $M_{\mathrm{MO}}$ is the molar weight of $\mathrm{MO}_{n}$. If hydrogen consumption reaches $100 \%$, the peak would assume a flat top. The use of eqn (2), however, indicates the region of near exhaustion, which is only the case in the deviant run (81). A similar criterium is derived recently by Monti and Baiker. ${ }^{19}$

The influence of sample weight, however, cannot be understood simply in terms of possible exhaustion of the feed. Gentry et al. ${ }^{12}$ observed a considerable change in their t.p.r. spectra with increasing sample weight. The two-step reduction of $\mathrm{Cu}^{2+}$ could not be resolved above a certain sample weight. Both at higher sample weights and at higher heating rates, a higher partial pressure of water vapour will be built up. Since the presence of water is known to enhance sintering processes, ${ }^{20}$ its presence might also be responsible for structural changes during reduction. Although Roozeboom et al..$^{13}$ have shown that water saturation of the feed did not cause a shift of their t.p.r. profiles, these profiles were found at a temperature $>200 \mathrm{~K}$ lower. The influence of water vapour at higher temperatures cannot be ruled out. In fact, the presence of water affects our t.p.r. profiles markedly, as shown in fig. 3, which also shows that too high a product of heating rate and sample weight $\left(\beta G_{\mathrm{MO} n}\right)$ affects the t.p.r. spectrum in the same way as does the addition of water vapour. This leads to the conclusion that at a choosen heating rate the sample weight should be as small as possible to keep a low partial pressure of water vapour.

A remarkable phenomenon is shown in fig. 2. The starting temperature of the first reduction peak is higher after prereduction and subsequent reoxidation of $\mathrm{V}_{2} \mathrm{O}_{5}$; however, the temperature at which the maximum reduction rate occurs is the same in both cases. Analogously, reduction of bulk $\mathrm{VO}_{2}$ starts at a relatively low temperature, while the reduction peak of $\mathrm{VO}_{2}$ formed as an intermediate product from reduced $\mathrm{V}_{6} \mathrm{O}_{13}$ does not show this behaviour. The fact that the peak maximum of the prereduced sample [fig. 2 , run $\left(b_{2}\right)$ ] does not shift excludes the possibility that this phenomenon reflects a rate-determining step before that involving the reduction of the bulk phase, otherwise the peak would have shifted to a lower temperature after this step was removed by the prereduction. The nature of this process, which will have 
a very low activation energy (concluded from the slope of the lower-temperature part), is not yet clear. Experiments on supported $\mathrm{V}_{2} \mathrm{O}_{5}$, not yet reported, show that this onset at a lower temperature is never observed in 'monolayer' catalysts.

In the case of the reduction of $\mathrm{NiO}$, Monti and Baiker ${ }^{19}$ describe this behaviour to an induction period during which stable nuclei are formed on the surface of the oxide. However, then the peak position would be affected by the pretreatment described above. The finding that the peak position is not influenced suggests that the virgin $\mathrm{V}_{2} \mathrm{O}_{5}$ (and also the $\mathrm{VO}_{2}$ ) contains structural irregularities which are removed by the preceeding reduction-oxidation cycle.

\section{CONCLUSIONS}

Calculations of apparent activation energies show that the reduction of bulk $\mathrm{V}_{2} \mathrm{O}_{5}$ is limited by solid-state diffusion. The highest resolution of the t.p.r. spectra is obtained at a relatively high heating rate and a small sample weight. It must be ascertained that no exhaustion of the feed takes place at the highest reduction rate and a rule of thumb has been supplied to provide for this. A pronounced influence of water, formed during the reduction, on the t.p.r. profiles of $\mathrm{V}_{2} \mathrm{O}_{5}$ is observed only at relatively high values of the product of heating rate and sample weight.

We thank Prof. G. C. Bond for many stimulating discussions, Prof. J. R. H. Ross for his helpful advice during the preparation of this manuscript and J. Boeysma for his skilful measurements of the X.r.d. patterns.

1 D. B. Dadyburjor, S. S. Jewur and E. Ruckenstein, Catal. Rev. Sci. Eng., 1979, 19, 293.

2 F. Roozeboom, P. D. Cordingly and P. J. Gellings, J. Catal., 1981, 68, 293.

3 A. J. van Hengstum, J. G. van Ommen, H. Bosch and P. J. Gellings, Appl. Catal., 1983, 8, 369.

4 P. Mars and D. W. van Krevelen, Chem. Eng. Sci., 1954, 3, 41.

5 W. H. M. Sachtler, G. J. H. Dorgelo, J. Fahrenfort and R. J. H. Voorhoeve, Proc. 4th Int. Congr. Catal. (Akademai Kiado, Budapest, 1971), vol. I, p. 454.

6 S. D. Robertson, B. D. McNicol, J. H. de Baas and S. C. Cloet, J. Catal., 1975, 37, 424.

J. W. Jenkins and B. D. McNicol, Chem. Technol., 1977, 7, 316.

8 N. W. Hurst, S. J. Gentry, A. Jones and B. D. McNicol, Catal. Rev. Sci. Eng., 1982, 24, 233.

${ }^{2}$ M. Bulens, Ann. Chim., 1976, 13.

10 R. Thomas, Thesis (University of Amsterdam, 1981).

11 H. C. Yao, J. Catal., 1979, 59, 365.

12 S. J. Gentry, N. W. Hurst and A. Jones, J. Chem. Soc., Faraday Trans. 1, 1979, 75, 1688.

${ }^{13}$ F. Roozeboom, M. C. Mittelmeyer-Hazeleger, J. A. Moulijn, J. Medema, V. H. J. de Beer and P. J. Gellings, J. Phys. Chem., 1980, 84, 2783.

14 G. C. Bond, personal communication.

15 G. L. Simard, J. F. Steger, R. J. Arnott and L. A. Siegel, Ind. Eng. Chem., 1955, 47, 1424.

16 E. Gillis, C. R. Acad. Sci., 1964, 258, 4765.

17 F. S. Stone, Oxide Crystal Chemistry and Catalysis, in Chemistry and Chemical Engineering of Catalytic Processes, ed. R. Prins and G. C. A. Schuyt (Sijthoff and Noordhoff, Alphenaan den Ryn, 1980), p. 477.

18 G. Anderson, Acta Chem. Scand., 1954, 8, 1599.

19 D. A. M. Monti and A. Baiker, J. Catal., 1983, 83, 323.

20 G. C. Kuczynski, L. Aberethy and J. Allan, in Kinetics of High-temperature Processes, ed. W. D. Kingery (Technology Press of M.I.T., Wiley, New York and Chapman and Hall, London, 1959), chap. 12.

21 N. Wagstaf and R. Prins, J. Catal., 1979, 59, 434.

22 V. C. F. Holm and A. Clark, J. Catal., 1968, 11, 305.

${ }_{23}$ P. J. G. Koopman, A. P. G. Kieboom and H. van Bekkum, J. Catal., 1981, 69, 172.

24 T. Paryjczak, J. Rynkowski and S. Karski, J. Chromatogr., 1980, 188, 254.

25 F. Mahoney, R. Rudham and J. V. Summers, J. Chem. Soc., Faraday Trans. 1, 1979, $75,314$.

26 A. J. Roosmalen, D. Koster and J. C. Mol J. Phys. Chem., 1979, 84, 3075.

27 A. Lycourghiotis, C. Defosse, F. Delanney, J. Lemaitre and B. Delmon, J. Chem. Soc., Faraday Trans. $1,1980,76,1677$. 